\title{
Facilitation of taxonomic recall in preschool children
}

\author{
MATTHEW J. SHARPS \\ California State University, Fresno, California
}

\begin{abstract}
Contrary to an older tradition of research, several recent studies have shown that preschool children are capable of conceptualizing item sets with respect to taxonomic, as well as thematic, relationships. The present study investigated the ability of preschool children to employ taxonomic relationships in free recall. Although the recall of thematic materials was shown to be superior to memory for taxonomically related items, taxonomic items, when supported by an orderly spatial arrangement, were recalled at a significantly higher level than were unrelated items. The results add to the growing body of research demonstrating that within appropriate research contexts, relatively abstract levels of conceptual organization may be utilized by preschool children.
\end{abstract}

A strong tradition of research holds that preschool children tend to classify items with respect to their thematic or functional relationships rather than by taxonomic properties, whereas school-age children become progressively better at taxonomic sorting (Bruner, Olver, \& Greenfield, 1966; Denney \& Moulton, 1976; Inhelder \& Piaget, 1964; Tversky, 1985; Vygotsky, 1934). This shift from "syntagmatic" (thematic or functional) to "paradigmatic" (taxonomic or superordinate) classification generally occurs in Western cultures at about 6 years of age (e.g., Kreye, 1984; Nelson, 1977; Smiley \& Brown, 1979).

More recent research, however, has shown that the syntagmatic-paradigmatic shift is more a question of preference than of capacity: Preschool children have repeatedly shown that they are capable of sorting items by taxonomic characteristics, although they generally have an easier time with thematically related items (Garrison, 1980; Markman, Cox, \& Machida, 1981; Scott, Greenfield, \& Urbano, 1985; Scott, Serchuk, \& Mundy, 1982; Smiley \& Brown, 1979). Children as young as 1-2 years of age have evidenced cognitive access to taxonomic conceptualization (Bauer \& Mandler, 1989), and the existence of the shift in any important sense at all has been questioned (Greenfield \& Scott, 1986).

A natural question arising out of work on conceptual organization is one that asks not so much whether young children have access to taxonomic categorization, but whether they can do anything with it. We addressed this question in a study directed toward ascertaining if preschool children could employ taxonomic relationships mnemonically (Sharps \& Gollin, 1985). Children were "primed" with

\footnotetext{
Preparation of this article was supported in part by a grant from California State University, Fresno. Requests for reprints should be addressed to M. J. Sharps, Department of Psychology, California State University, Fresno, CA $93740-0011$.
}

taxonomic or thematic relationships and were then asked to remember taxonomically and thematically related items. Taxonomic priming did not aid recall above control levels in any of the several conditions of the experiments. However, taxonomic priming was shown to influence children's intrusions-that is, items that they thought they remembered but that were not in fact presented. Children in the taxonomic priming condition tended to respond with intrusions that were taxonomically related to the materials presented. This indicated, as would be expected from recent literature, that preschool children were able to access taxonomic relationships within the memory paradigm employed, although this access did not actually influence recall effectiveness.

Given that preschoolers appear to understand taxonomic relationships, at least in some sense, within a recall paradigm, it seemed likely that they would be able to make mnemonic use of such relationships within an appropriate supportive task framework. It was suggested that such a framework might be found within the area of spatial memory. Preschool children, including children as young as 3 months of age (Hayne, Rovee-Collier, \& Borza, 1991), have repeatedly shown an ability to use spatial organization and spatial cues in memory easily (e.g., Mandler, Seegmiller, \& Day, 1977; von Wright, Gebhard, \& Karttunen, 1975; West, Morris, \& Nichol, 1985). Therefore, it seemed probable that the provision of a spatial framework for memory might enable preschool children to employ taxonomic relationships to enhance recall. The present study tested this hypothesis.

\section{EXPERIMENT 1}

To assess children's responses to taxonomically and thematically related stimuli, it was, of course, first necessary to obtain items from thematic, taxonomic, and unrelated categories and to examine the responses of preschool children to these items in the absence of spatial support for memory. This was the goal of Experiment 1. 


\section{Method}

Three sets of line drawings, 20 drawings per set, were obtained. These were a taxonomic set (taken from a typical taxonomic category-e.g., animals), a thematic set (taken from a typical thematic category-e.g., things found or used in a schoolroom), and an unrelated set (drawings that bore no evident normal categorical interrelatedness-e.g., flowers, hammer, bathtub, baseball). The drawings from the three sets were shown not to differ with respect to concreteness, imagery, or meaningfulness, characteristics that, by means of the norms of Paivio, Yuille, and Madigan (1968), could have influenced their memorability. Pilot data drawn from 6 adult and 6 preschool subjects indicated that the unrelated items were genuinely unrelated: No "categories" of more than two items were created by any of the pilot subjects. The drawings for each set were mounted on uniform $10 \times 10 \mathrm{~cm}$ cards, 1 drawing per card.

The subjects were 18 children (mean age 5 years, range 4-6 years, divided equally by sex) who were recruited from private preschools and day-care centers. The children participated individually. They were told that they would be shown some pictures and that they were to remember them because they would be asked about them later. Then the children were shown the unrelated drawings, the taxonomic drawings, or the thematic drawings, sequentially and for $3 \mathrm{sec}$ each, in a completely between-subject design. The items were named by the experimenter as they were presented. Then the children were asked to recount verbally the items that they had seen.

\section{Results and Discussion}

The effect of category type was significant $[F(2,15)=$ $\left.7.64, p=.005, \omega^{2}=.42\right]$. Tukey's honestly significant difference $(H S D)$ analysis $(p<.05)$ confirmed that thematic items [mean recall score 8.67, standard deviation $(S D) 1.03$ ] were recalled at a significantly higher level than were taxonomic items (M 5.67, SD 1.03) and unrelated items ( $M$ 5.83, SD 2.14), which were statistically indistinguishable. No detectable or significant differences resulted from the age or sex of the subjects.

The results confirmed that the categorical organization of the taxonomic set was of no use mnemonically to the preschoolers of this experiment. The taxonomic set was recalled at a level even lower, although not significantly so, than that at which the unrelated set was recalled. In contrast, thematic organization was useful for the children's recall: The thematic set was recalled at a significantly higher level than either of the other two sets, producing a very large effect size $\left(\omega^{2}\right)$.

Obviously, these results might not extrapolate to all possible sets of thematically and taxonomically related stimuli. Under the appropriate circumstances, it might very well be possible to find sets of taxonomically related items that were more memorable than thematically related items. However, what has been established by Experiment 1 is that, employing these stimuli with the present paradigm, thematic relationships were mnemonically useful to preschool children and taxonomic relationships were mnemonically useless. It remained, then, to find out whether taxonomic relationships could be given mnemonic value within this paradigm and in this age group.

\section{EXPERIMENT 2}

\section{Method}

The subjects were 33 children. They were of the same ages and characteristics, and from the same sources, as were the subjects in Experiment 1. Copies of the three sets of drawings used in Experiment 1 were made. Each set was glued, in a $4 \times 5$ evenly spaced matrix, to a $55 \times 70 \mathrm{~cm}$ piece of white posterboard. These formed an "unrelated array," a "taxonomic array," and a "thematic array." Instructions and procedures were essentially identical to those used in Experiment 1 . The children, again participating individually, were presented with one of the three arrays and asked to remember the items. The experimenter named and pointed out the items, sequentially, for $3 \mathrm{sec}$ each.

\section{Results and Discussion}

The effect of stimulus type was significant $[F(2,30)=$ 23.66, $p<.001, \omega^{2}=.59$ ]. Tukey's $H S D$ analysis $(p<.05)$ showed that thematic items (mean recall score $10.18, S D$ 1.99) were recalled at a significantly higher level than were either taxonomic items (M 7.55, SD 0.82) or unrelated items ( $M$ 6.00, SD 1.26). Also, consistent with the hypothesis advanced above, taxonomic items were recalled at a significantly higher level than were unrelated items. Given the sample size $(N=33)$ and the fact that this finding was demonstrated by the relatively conservative $H S D$ test, it would appear that an appropriate spatial framework for recall can make it possible for preschool children both to employ taxonomic relationships mnemonically and to understand them within sorting paradigms.

\section{GENERAL DISCUSSION}

Gollin (e.g., 1981, 1984) has repeatedly called for the "age-by-task" analysis of cognitive development, within which subjects at different ages are tested along a continuum of systematically varied experimental tasks. This makes the detection of previously unsuspected competencies on the part of developing organisms more likely for the simple reason that such competencies may manifest themselves under some sets of experimental circumstances but not under others.

Viewed from the age-by-task perspective, the syntagmatic-paradigmatic shift emerges neither as a critical developmental landmark nor as an unimportant artifact of changes in children's interests or preferences. Rather, the importance and magnitude of the shift varies with different task frameworks. In the present study, when items were presented sequentially without spatial support, no ability to use taxonomy to support memory was observed. Similar findings were obtained in earlier work (Sharps \& Gollin, 1985), directed toward attempting to prime children toward taxonomic memory. However, in the presence of a spatial framework, a type of support for memory that children exploit easily, the preschoolers of the present study were capable of employing taxonomic relationships to support their recall, although not to the level observed with thematic relationships. It may be that similar age-bytask considerations also apply both to the voluminous literature on taxonomic and thematic sorting by preschoolers and to recall, as in the present study.

It should be pointed out that the present results should not be expected to extrapolate to all possible experimental frameworks. For example, research paradigms within which subjects from preschool to adolescence appear to 
prefer thematic categorization (e.g., Greenfield \& Scott, 1986), or within which thematic information appears as difficult of access as taxonomic relationships (e.g., Bauer \& Mandler, 1989), might very well lead to different findings in the presence of spatial memory support. However, it must be remembered that disparate results need not reflect either natural or methodological chaos. Such outcomes may merely reflect the complex interaction of developmental and task-related variables within different experimental frameworks. A systematic analysis of the interactive operation of relevant age- and task-related variables, within and between the relevant frameworks, should ultimately result in an improved understanding of the conditions under which different types of conceptual organization become accessible, useful, or preferred in the developing child.

\section{REFERENCES}

BAuer, P. J., \& MANDler, J. M. (1989). Taxonomies and triads: Conceptual organization in 1 to 2-year-olds. Cognitive Psychology, 21, 156-184.

Bruner, J. S., Olver, R. R., \& Greenfield, P. M. (1966). Studies in cognitive growth. New York: Wiley.

Denney, D. R., \&oulton, P. A. (1976). Conceptual preferences among preschool children. Developmental Psychology, 12, 509-513.

GARRISON, A. (1980). Categorical and spatial models of representation in young children's recall. Journal of Experimental Child Psychology, 30, 383-388.

GoLLIN, E. S. (1981). Development and plasticity. In E. S. Gollin (Ed.), Developmental plasticity: Behavioral and biological aspects of variations in development. New York: Academic Press.

GoluIN, E. S. (1984). Developmental malfunctions: Issues and problems. In E. S. Gollin (Ed.), Malformations of development: Biological and psychological sources and consequences. New York: Academic Press.

GREENFIELD, D. B., \& ScotT, M. S. (1986). Young children's preference for complementary pairs: Evidence against a shift to a taxonomic preference. Developmental Psychology, 22, 19-21.

HAYNe, H., Rovee-Collier, C., \& BorzA, M. A. (1991). Infant memory for place information. Memory \& Cognition, 19, 378-386.
INHelder, B., \& PIAGET, J. (1964). The early growth of logic in the child: Classification and seriation. London: Routledge.

KREYE, M. (1984). Conceptual organization in the play of preschool children: Effects of meaning, context, and mother-child interaction. In I. Bretherton (Ed.), Symbolic play: The representation of social understanding. New York: Academic Press.

Mandler, J. M., Seegmiler, D., Day, J. (1977). On the coding of spatial information. Memory \& Cognition, 5, 10-16.

Markman, E., Cox, B., Machida, S. (1981). The standard objectsorting task as a measure of conceptual organization. Developmental Psychology, 17, 115-117.

NeLSON, K. (1977). The syntagmatic-paradigmatic shift revisited: A review of research and theory. Psychological Bulletin, 84, 93-116.

Paivio, A., Yullie, J., \& Madigan, S. (1968). Concreteness, imagery, and meaningfulness values for 925 nouns. Journal of Experimental Psychology Monographs, 76(1, Pt. 2).

SCott, M. S., Greenfield, D. B., \& URBANo, R. (1985). A comparison of complementary and taxonomic utilization: Effects of the dependent measure. International Journal of Behavioral Development, 8, 241-256.

Scott, M. S., Serchuk, R., MUNDy, P. (1982). Taxonomic and complementary picture pairs: Ability in two- to five-year olds. International Journal of Behavioral Development, 5, 243-256.

Sharps, M. J., \&ollin, E. S. (1985). Memory and the syntagmaticparadigmatic shift: A developmental study of priming effects. Bulletin of the Psychonomic Society, 23, 95-97.

Smiley, S. S., Brown, A. L. (1979). Conceptual preference for thematic or taxonomic relations: A nonmonotonic age trend from preschool to old age. Journal of Experimental Child Psychology, 28, 249-257.

TVersKy, B. (1985). Development of taxonomic organization of named and pictured categories. Developmental Psychology, 21, 1111-1119.

von Wright, J. M., Gebhard, P., \& KartTunen, M. (1975). A developmental study of the recall of spatial location. Journal of Experimental Child Psychology, 20, 181-190.

VYGOTSKY, L. S. (1934). Thought and language. New York: Wiley.

WeST, R. L., MorRIs, C. W., \& Nichol, G. T. (1985). Spatial cognition on nonspatial tasks: Finding spatial knowledge when you're not looking for it. In R. Cohen (Ed.), The development of spatial cognition. Hillsdale, NJ: Erlbaum.

(Manuscript received October 4, 1991.) 